\title{
OS IMPACTOS DA INTERNACIONALIZAÇÃO DA ECONOMIA NO UNIVERSO DO TRABALHO: UMA NECESSÁRIA REFLEXÃO SOB O VIÉS DA VALORIZAÇÃO DO TRABALHO E DA DIGNIDADE HUMANA
}

\author{
THE IMPACTS OF THE INTERNATIONALIZATION OF THE ECONOMY IN THE \\ UNIVERSE OF WORK: A NECESSARY REFLECTION ACCORDING TO THE \\ VALORIZATION OF WORK AND HUMAN DIGNITY
}

\author{
1NELMA KARLA WAIDEMAN FUKUOKA \\ ${ }^{2}$ VICTOR HUGO DE ALMEIDA
}

\section{RESUMO}

A atual crise econômica brasileira tem afetado substancialmente as relações entre o capital e o trabalho nos últimos anos. Neste panorama, o presente artigo tem por objetivo examinar os impactos da internacionalização da economia no universo do trabalho sob o viés dos ditames da valorização do trabalho e da dignidade humana insculpidos na Constituição Federal de 1988, bem como a papel da função social da empresa nesse contexto. A contemporaneidade do assunto, assim, parece inquestionável, notadamente quando se verifica que a efetividade dos direitos fundamentais trabalhistas constitui um dos principais clamores públicos da atualidade.

Palavras-chave: Direito do trabalho; crise econômica; desemprego; valorização do trabalho; dignidade humana.

\begin{abstract}
Brazil's current economic crisis has severely affected the relations between capital and labor in recent years. Against this background, this paper aims to examine the impact of the internationalization of the economy in world of work according to labor valuing dictates and human dignity sculptured in the Federal Constitution of 1988 and the role of the social function of the company that context. The contemporaneity of the subject thus seems unquestionable, especially when it appears that the effectiveness of labor fundamental rights is a major public outcries today.
\end{abstract}

Keywords: labor law; economic crisis; unemployment; valuation of human work; human dignity.

${ }^{1}$ Mestranda em Direito pela Universidade Estadual Paulista (UNESP/Franca), Franca, São Paulo, Brasil. Email: nelmawf@terra.com.br

${ }^{2}$ Doutor em Direito pela Universidade de São Paulo (USP), São Paulo, Brasil. Docente em Ciências Humanas e Sociais pela Universidade Estadual Paulista (UNESP/Franca), Franca, São Paulo, Brasil. Email: victorhugo.professor@gmail.com 


\section{INTRODUÇÃO}

A economia mundial vem enfrentando uma de suas crises mais graves. Potências mundiais, antes robustas e inabaláveis, têm vivenciado situações inesperadas, tais como variações na bolsa de valores, desemprego, instabilidade econômica e crises internas, criando um movimento econômico que afeta todo o globo e prejudica principalmente os trabalhadores.

No cenário brasileiro atual, não é raro se noticiar a ocorrência de dispensas envolvendo um grande número de trabalhadores. As justificativas quase sempre têm se baseado em fatores vinculados à situação econômica do país.

Neste panorama, o presente artigo tem por objetivo examinar os impactos da internacionalização da economia no mercado de força do trabalho e, sobretudo, nos direitos fundamentais da classe trabalhadora, sob o viés dos ditames da valorização do trabalho e da dignidade humana insculpidos na Constituição Federal de 1988, bem como a papel da função social da empresa nesse contexto.

Como método de procedimento, adotou-se o levantamento por meio da técnica de pesquisa bibliográfica em materiais publicados (por exemplo, doutrinas, legislação, artigos, matéria publicadas em jornais/revistas/sítios eletrônicos, dissertações, entre outros). E, como método de abordagem, adotou-se o método dialético, visando à compreensão e a interpretação crítica e aproximada da realidade, partindo do pressuposto de que esta é historicamente superável. A visão dialética deve ser compreendida pelo dinamismo do raciocínio por entre a materialidade histórica, que trata da organização social ao longo da história da humanidade (LAMY, 2011).

A estrutura do presente artigo compreende, primeiramente, a dispensa coletiva como fenômeno decorrente da crise econômica; e posteriormente, as consequências nefastas do desemprego. Por conseguinte, aborda-se a proteção social do trabalhador, frente à supremacia econômica do empregador, sob o viés da efetivação do valor social do trabalho e do princípio da dignidade humana e, por fim, a estreita relação entre crise econômica, função social da empresa e dispensa coletiva.

Desse modo, a contemporaneidade do assunto parece inquestionável, notadamente quando se verifica que a efetividade dos direitos fundamentais trabalhistas constitui um dos principais interesses clamores públicos da atualidade. 


\section{Crise econômica e dispensa coletiva}

A crise econômica global de 2008 evidenciou o desacerto do sistema capitalista, afetando gravemente as relações entre o capital e o trabalho. Tal panorama também se intensificado no Brasil nos últimos anos.

O desemprego, como fenômeno coletivo que atualmente se mostra, é coetâneo da moderna economia capitalista, apresentando-se como fenômeno estrutural em razão da extrema divisão do trabalho, dos métodos de produção, da distribuição e da acumulação de renda (COSTA, 1991). O uso da tecnologia e a exigência de trabalhadores extremamente qualificados, como heranças do modelo toyotista, cria um exército de reserva, pronto para ocupar postos de trabalho, cada vez mais raros, elevando as taxas de desemprego no contexto global (GONÇALVES; KNEIPP, 2013).

Nas palavras de Enoque Ribeiro dos Santos (2006, p. 83):

É inegável que a globalização da economia e seus efeitos - abertura dos mercados, aumento da concorrência, maior fluidez financeira, transferência de propriedade, novas tecnologias, introdução de novos procedimentos eletrônicos e de informatização, diminuição das margens de benefícios concedidos aos empregados, alteração da política de pessoal - ocasionam maior descentralização das empresas e são responsáveis não apenas pelo recrudescimento do nível de desemprego na economia, como também por transformações profundas no mercado de trabalho.

Neste contexto, é imperioso considerar os fatos políticos, econômicos e sociais decorrentes da globalização econômica, que têm imposto uma revisão crítica do processo judicial. Dentre eles está a crise econômica de 2008 e 2009, que se originou da tendência do mercado financeiro de crescer além do que permitem os recursos da economia real, conforme evidencia Paul Singer (1968, p. 158):

Desde o seu início está o capitalismo sujeito a crises e, a partir do momento em que ele passou a dominar a economia de várias nações, estas crises adquiriram caráter cíclico e passaram a desempenhar um papel decisivo no que se refere à compreensão crítica do funcionamento do sistema.

Por crise se entende algo eventual, passageiro e esporádico. E os riscos econômicos do empreendimento são sempre do empregador, conforme preleciona o art. $2^{\circ}$ da Consolidação das Leis do Trabalho (CLT). Assim, pertencendo ao empregador os riscos do negócio, não se pode transferi-los aos empregados, nem mesmo em épocas de acentuadas turbulência. Tais riscos 
sequer podem afetar os direitos dos trabalhadores, embora possam influenciar a continuidade do contrato de trabalho, caso a empresa encerre suas atividades (MARTINS, 2000).

Apesar disso, os órgãos midiáticos constantemente noticiam reações das empresas à crise através de demissões em massa, corte de custos, fechamento de estabelecimentos, dentre outras medidas extremas.

No entanto, o núcleo de uma crise global não repousa na fria análise mercadológica, mas, sim, num aprofundamento das desigualdades sociais, na equidistância da justiça social e no empobrecimento da classe trabalhadora (SOUTO MAIOR, 2000). Diante dessas inseguranças do mundo do trabalho, o desemprego se mostra como a ponta mais visível desse verdadeiro iceberg (MATTOSO, 1996), de acordo com Jorge Luiz Souto Maior (2000, p. 181):

O problema do desemprego deve ser tratado com eficiência. Não se pode reduzi-lo a resultado de mera operação matemática: menor custo, menor desemprego, pois que isso representa um engodo, não elimina o problema e, por causa da precarização das relações de trabalho, gera outro problema, qual seja, o aumento do fosso (um verdadeiro abismo) entre ricos e pobres, aumentando a cada dia o número de pobres.

É evidente que a estrutura atual não consegue absorver o desemprego com o necessário equilíbrio, já que a atual lógica global favorece o desemprego e a diminuição do rendimento daquele que ainda consegue trabalho. Numa análise qualitativa do desemprego, nota-se que os empregos mais qualificados se preservam para os segmentos de renda mais alta, embora em dimensão insuficiente para permitir a contínua mobilidade socioprofissional. O resultado disso se apresenta no "aprofundamento da crise de reprodução social no interior do mercado de trabalho" (ANTUNES, 2011, p. 122), conforme esclarece Ana Paula Tauceda Branco (2007, p. 19):

É certo que a mencionada crise atingiu, em cheio, a regulação das relações individuais e coletivas de trabalho humano, propondo-lhe mutações, por vezes teratogênicas, em nome da "modernização" de seus fundamentos elementares e - quiçá - das premissas constitucionais vigentes, na medida em que atinge e afeta, violentamente, a proteção de direitos fundamentais constitucionais.

Todavia, para Souto Maior, o consequente achatamento das garantias sociais não se dá em virtude de crise, pois os lucros do capital têm sido cada vez maiores, mas em virtude da concorrência internacional (SOUTO MAIOR, 2000). Por sua vez, a mudança na natureza do trabalho também tem contribuído para a insegurança econômica dos trabalhadores, uma vez que muitos deles já não conseguem encontrar empregos com jornada integral e duração indeterminada (RIFKIN, 1995). Disto, pode-se concluir que o Direito do Trabalho acaba se 
tornando a seara jurídica mais suscetível às transformações decorrentes do processo de globalização (GODOY, 2003).

\section{0 desemprego e suas consequências}

Na tradição keynesiana, a discussão conceitual sobre o desemprego se limita a uma análise do desemprego involuntário, isto é, dos que oferecem força de trabalho disponível aos salários vigentes e não encontram aproveitamento. Esse conceito, em seu uso original, liga-se aos períodos de declínio da demanda agregada, principalmente em países capitalistas desenvolvidos, onde esse desemprego tem sido, em grande parte, de caráter cíclico (HOFFMAN, 1980), quando, subitamente, a mão invisível do mercado falha (SINGER, 1968).

O despedimento do obreiro, quando ocorre pela manifestação volitiva lícita do empregador, representa, além dos números, uma profunda significação social, apresentando-se como forma de desequilíbrio social. Por meio dela, os empregados perdem seus empregos involuntariamente, e, consequentemente, o único meio de subsistência. E quando o desemprego perdura, pode haver consequências degradantes para quem se vê obrigado a ficar parado (SINGER, 1968).

A morte da força de trabalho global está sendo interiorizada por milhões de trabalhadores que experimentam sua própria morte individual, diariamente, nas mãos de empregadores que visam exclusivamente ao lucro e nas garras de um governo desinteressado. São aqueles que esperam o bilhete azul e, então, são forçados a trabalhar em jornada parcial mediante salário reduzido ou são empurrados para as filas do seguro-desemprego. A cada nova indignidade, sua confiança e sua autoestima sofrem mais um golpe; tornam-se descartáveis, depois irrelevantes e, finalmente, invisíveis (RIFKIN, 1995).

Porém, considera-se prejudicial, inclusive para a sociedade, que uma parte da população ativa encontre-se durante certo período desempregada, já que na perspectiva macroeconômica o desemprego também implica um alto custo, em razão da produção que poderia ter sido efetivada (MACHÓN MORCILLO; TROSTER, 1994).

Numa análise globalizada, aponta Sérgio Pinto Martins (2000) que a perda de empregos gera uma cadeia de danos, envolvendo o trabalhador (diminuição do padrão de vida para sua família com a perda da renda; sentimento de inutilidade, desprestígio, impotência e rejeição social, podendo ocasionar problemas familiares e doenças; surgimento de problemas sociais, como a criminalidade, por exemplo); a empresa (pode representar a diminuição da 
produtividade; perda de trabalhadores qualificados, treinados e capacitados; redução do consumo); e também o Governo (aumentos de recursos destinados ao seguro-desemprego, gerando a necessidade do aumento da carga tributária para esse fim; diminuição do número de trabalhadores recolhendo sua parte da contribuição previdenciária, havendo diminuição na arrecadação da citada exação; o desempregado continua usando os benefícios que a saúde pública proporciona, sem estar contribuindo; há queda da produtividade nacional e, consequentemente, do Produto Interno Bruto (PIB); aumento da criminalidade e da miséria em certas regiões; diminuição do crescimento econômico do país).

A partir desse diagnóstico, pode-se concluir que os trabalhadores, além de seres humanos que devem ser respeitados e ter sua dignidade protegida, possuem um alto valor para a economia, pois são, na essência, os consumidores que o capitalismo precisa para se manter vivo. Ou seja, "a produção necessita do consumidor e necessita, portanto, do trabalhador" (SOUTO MAIOR, 2000, p. 160).

\section{0 valor social do trabalho e a efetivação do princípio da dignidade humana}

O trabalho é inerente ao ser humano e a ele está relacionado desde o início dos tempos. Por meio dele o ser humano se transforma e transforma o mundo.

O trabalho, no entendimento de Enoque dos Santos Ribeiro (1999), possui duas faces, como uma moeda: por um lado, geralmente, ele é um serviço ou uma atividade, prestado por um homem ou uma mulher em uma organização, uma empresa, ou ainda uma pessoa física; de outro lado, para a maioria dos indivíduos ele é a principal fonte de renda. Graças a esta dupla natureza que o trabalho se diferenciaria dos outros bens e serviços colocados à disposição dos consumidores nos outros mercados, já que, como fonte de renda, ele desempenharia um importante papel na distribuição do nível de vida no seio de uma coletividade.

Na perspectiva do Direito, segundo José Antônio Pancotti (2009), a atividade humana relativa ao trabalho incorpora, pelo menos, os cinco seguintes enfoques ou valores: econômico (é fonte de criação de renda e propicia o consumo de bens e serviços para a satisfação das necessidades humanas; fator ou elemento de custo da produção), jurídico (é um fator de criação de relação jurídica, fonte de direitos e obrigações entre o prestador e o tomador de serviços), político (é fator de crescimento da economia do Estado que o capacita a propiciar o bem-estar geral da coletividade), sociológico (é fator que propicia a maior intensidade de desenvolvimento, a expansão de contatos sociais e a inclusão social das classes trabalhadoras) 
e psicológico (fator trabalho é oportunidade de expansão e aperfeiçoamento da personalidade, fonte de projeção e afirmação social).

Nessa seara, apesar de a Constituição Federal (BRASIL, 1988) prever uma série de garantias a esta classe, os fatores políticos atrelados aos econômicos impedem que estes direitos sejam fielmente efetivados. Por vezes, o Direito do Trabalho é menosprezado pelos próprios juristas.

É desencadeado um ciclo. O trabalhador desamparado e desmotivado não alcança o rendimento esperado, o que pode ocasionar a dispensa do mesmo. Desempregado, ele não consome o mesmo que consumiria se possuísse um emprego, afetando assim, a economia. $\mathrm{E}$ mesmo que não fosse dispensado, o baixo rendimento causa reflexos na produção, o que também atinge a economia. A condição de vida da classe trabalhadora se torna, então, um termômetro econômico e social.

Nos últimos anos, o Brasil tem sido palco de uma violente crise econômica, com a consequente piora das condições de trabalho em vários aspectos da relação de emprego. Nesse quadro, vive o trabalhador brasileiro à beira da miséria pelos baixíssimos salários que recebe, trabalhando, quase sempre, em péssimas condições ambientais.

Em muitas vezes, o emprego, além de representar a única fonte da sua própria subsistência e de sua família, representa, antes de tudo, a base de sua existência e da sua própria dignidade como pessoa humana. Nessa direção, pontua Ana Paula Tauceda Branco (2007, p. 61):

[...] não constitui o homem uma 'máquina', nem o trabalho unicamente uma 'mercadoria', ou, na acepção moral, cultural ou religiosa tão-somente um fardo, um encargo, um castigo, uma dívida, uma pena, mas antes e, sobretudo, um valor dignificação do trabalho - que fundamenta os Direitos Fundamentais do Homem na sua formação cultural e que é sustentado por dois vieses concomitantes inerentes ao Direito e à Moral.

A Teoria dos Direitos Fundamentais do Homem funda-se na premissa do mínimo necessário para que o ser humano possa viver com dignidade a ponto de desenvolver, nos ensaios da experiência da vida, sua essência e sua personalidade, não se ocupando somente com a subsistência desse ser humano, mas também com a sua realização plena através de cada conquista alcançada e de cada valor que passa, dinamicamente, a agregar a existência e a potencialidade humanas (BRANCO, 2007). 
A dignidade da pessoa humana é inerente a sua própria condição. Por isso, é indubitável que os ideais trabalho e dignidade humana são indissociáveis, sendo os direitos sociotrabalhistas uma parcela dos direitos fundamentais. E a dignidade do trabalhador, como ser humano, deve ter profunda ressonância na interpretação e aplicação das normas legais e das condições contratuais de trabalho, uma vez que o trabalho sem dignidade pode rebaixar o ser humano à condição análoga à de escravo ou até mesmo à de animal.

O pressuposto da proteção social do trabalhador, frente à supremacia econômica do empregador, expressão da desigualdade jurídica, é uma forma de colocar em situação de relativa igualdade os dois polos da relação de trabalho. Para Maurício Godinho Delgado (2011), o trabalho com garantias mínimas - que no mundo capitalista tem se confundido com o emprego, ao menos para os despossuídos de poder socioeconômico - torna-se, na prática, o grande instrumento de alcance no plano social da dignidade humana.

Ao lado do direito à vida, a dignidade humana constitui o núcleo essencial dos direitos humanos, fundamentando e conferindo unidade não apenas aos direitos fundamentais, mas também à organização econômica. Trata-se de um primado claramente evidenciado no sistema da Constituição Federal de 1988, no qual a dignidade da pessoa humana é adotada em dois momentos: como fundamento da República Federativa do Brasil (art. $1^{\text {o }}$, III) e como fim da ordem econômica (art. 170, caput), conforme expõe Eros Grau (2008, p. 198-199):

\begin{abstract}
A dignidade da pessoa humana comparece, assim, na Constituição de 1988, duplamente: no art. $1^{\circ}$ como princípio político constitucionalmente conformador (Canotilho); no art 170, caput, como princípio constitucional impositivo (Canotilho) ou diretriz (Dworkin) - ou, ainda, direi eu, como norma-objetivo. Nesta sua segunda consagração constitucional, a dignidade da pessoa humana assume a mais pronunciada relevância, visto comprometer todo o exercício da atividade econômica, em sentido amplo - e em especial, o exercício da atividade econômica em sentido estrito - com o programa de promoção da existência digna, de que, repito, todos devem gozar. Daí porque se encontram constitucionalmente empenhados na realização desse programa - dessa política pública maior - tanto o setor público quanto o setor privado. Logo, o exercício de qualquer parcela da atividade econômica de modo não adequado àquela promoção expressará violação do princípio duplamente contemplado na Constituição.
\end{abstract}

Nesse sentido, também pontua Ana Paula Tauceda Branco (2007, p. 62):

Partindo da premissa de que uma das funções dos Princípios Constitucionais Fundamentais é orientar, vasta e adequadamente, a interpretação e a aplicação das normas jurídicas, há que ser vencida essa dificuldade de assimilar uma postura hermenêutica tendente a reconstruir, nos casos concretos, uma unidade textual da Carta Constitucional capaz de sustentar, em todos os níveis, o trabalho humano como valor social a ser respeitado pelo Estado e por particulares nas mais diversas dimensões de suas atividades sociais, reconhecendo-lhes sentido, importância e 
reverência como natural faceta do Princípio Constitucional vetorial que é o da Dignidade da Pessoa Humana.

A Constituição Federal de 1988, complementando o art. 170, caput, ainda reafirma a supremacia do valor social do trabalho evidenciado como fundamento da República Federativa do Brasil, conforme dispõe o art. $1^{\circ}$, inciso IV, da Lei Maior.

Segundo Eros Grau (2008), a interação entre esses dois princípios e os demais por ela contemplados - particularmente o que define como fim da ordem econômica (mundo do ser) assegurar a todos existência digna - resulta que valorizar o trabalho humano e tomar como fundamental o valor social do trabalho acarreta um tratamento peculiar ao trabalho e a seus agentes (os trabalhadores). Diante disso, assevere Ana Paula Tauceda Branco (2007, p. 62):

O Princípio do Valor Social do Trabalho não constitui tão-somente uma regra juridicamente ordenada, mas antes um "cordão umbilical" em que o Sistema é realimentado pelo Princípio Constitucional Fundamental da Dignidade da Pessoa Humana que, a nosso ver, inegavelmente, ocupa local e função (informadora, normativa e interpretadora) em primazia às demais normas, vinculando-as posicionamentos hermenêuticos que reconheçam a pessoa humana, especialmente na figura do trabalhador e do seu trabalho, como pilar estruturante do Sistema.

Note-se que o referido valor, previsto como princípio constitucional pelo ordenamento jurídico pátrio, vem expresso não somente no título referente aos Princípios Fundamentais da República, mas, também, no título relativo à Ordem Econômica e Financeira (BRANCO, 2007), afirmando estar a ordem econômica fundada na valorização do trabalho humano. Diante disso, esclarece José Afonso da Silva (2011, p. 286):

Não é fácil estremar, com nitidez, os direitos sociais dos direitos econômicos. [...] em verdade, o trabalho é um componente das relações de produção e, nesse sentido, tem dimensão econômica indiscutível. A Constituição tomou partido a esse propósito, ao incluir os direitos dos trabalhadores como espécie dos direitos sociais, e o trabalho como primado básico da ordem social (art. $7^{\circ}$ e 193). É a posição correta.

O inciso VIII do art. 170 estabelece o princípio da busca do pleno emprego, já previsto desde a Declaração Universal dos Direitos do Homem, conforme se extrai do $1^{\circ}$ do art. XXIII: "todo homem tem direito ao trabalho, à livre escolha de emprego, a condições justas e favoráveis de trabalho e à proteção contra o desemprego" (ONU, 1948, online).

Em regra, tal princípio apenas é mencionado como um mero desdobramento do princípio constitucional fundamental do valor social do trabalho (BRANCO, 2007). Contudo, como afirma André Ramos Tavares (2006), a busca do pleno emprego, juntamente com a justiça 
social, deve servir base para a interpretação de todos os direitos trabalhistas contidos na Constituição de 1988. Ademais:

\begin{abstract}
Independentemente de se entender o rol indicado pelo art. 170 da Constituição como contemplativo todo ele de princípios, é certo que nele se albergam, por expressa menção constitucional, não apenas os fundamentos da ordem econômica, mas igualmente finalidades, ou seja, os objetivos a serem atingidos por meio da implementação de seus ditames econômicos. [...] Assim, o objetivo a ser buscado, consoante a Constituição, é dúplice, englobando a procura de uma existência digna e consoante os ditames da justiça social. (TAVARES, 2006, p. 128-129).
\end{abstract}

Para a OIT, o pleno emprego é fundamental para a erradicação da pobreza e da fome. A população teria direito ao pleno emprego e caberia à sociedade estabelecer leis e normas que possibilitassem a utilização integral da oferta de trabalho, desde que o pleno emprego é uma condição necessária para a restauração da dignidade dos trabalhadores e uma condição essencial para a estabilidade e o progresso da sociedade (KON, 2012). E, ainda:

\begin{abstract}
A busca do pleno emprego é um princípio diretivo da economia que se opõe às políticas recessivas. Pleno emprego é expressão abrangente da utilização, ao máximo grau, de todos os recursos produtivos. Mas aparece, no art. 170, VIII, especialmente no sentido de propiciar trabalho a todos quantos estejam em condições de exercer uma atividade produtiva. Trata-se do pleno emprego da força de trabalho capaz. Ela se harmoniza, assim, com a regra de que a ordem econômica se funda na valorização do trabalho humano. Isso impede que o princípio seja considerado apenas como mera busca quantitativa, em que a economia absorva a força de trabalho disponível, como o consumo absorve mercadorias. (SILVA, 2011, p. 799).
\end{abstract}

Assim sendo, numa clara opção de legitimar o valor social do trabalho, o constituinte instituiu, incansavelmente, o primado do trabalho humano sob um prisma categórico, também como base da Ordem Social, cujo preceito encontra-se insculpido no art. 193 da Constituição Federal.

O valor social do trabalho, como um dos princípios constitucionais que fundamentam nossa República, há de ser experimentado pela pessoa humana tanto no âmbito da sociedade como no da economia, numa exploração de conteúdos que requerem a necessidade de conjugar uma relação de complementaridade e tensão entre os aspectos de direito e de dever do trabalho humano (BRANCO, 2007).

De tal modo, abarca em si tanto a dimensão do direito a manter uma vida humana por meio da sobrevivência oportunizada por esse mesmo trabalho, como também a dimensão de dever, uma vez que a sociedade necessita da contribuição de todos para o seu adequado funcionamento e para a harmonização social (TAVARES, 2006).

Nas palavras de Manoel Gonçalves Ferreira Filho (2010, p. 387): 


\begin{abstract}
Na verdade, o trabalho é ao mesmo tempo um direito e uma obrigação de cada indivíduo. Como direito, deflui diretamente do direito à vida. Para viver, tem o homem de trabalhar. A ordem econômica que lhe rejeitar o trabalho, lhe recusa o direito a sobreviver. Como obrigação, deriva do fato de viver o homem em sociedade, de tal sorte que o todo depende da colaboração de cada um.
\end{abstract}

Nessa senda, se os direitos sociotrabalhistas constituem autênticos direitos fundamentais da pessoa humana do ordenamento jurídico, é exatamente nessa espécie de direitos que nosso Estado encontra sua própria razão de ser, motivo pelo qual se deve, a respeito deles, ser defendida sua inquestionável efetividade (BRANCO, 2007). No entanto, há de se observar que:

\footnotetext{
Um equívoco hermenêutico vem sendo, constantemente, cometido, qual seja: atrelar o valor do trabalho humano às possibilidades econômicas e não em correspondência às necessidades humanas.

Ao contrário, esse mesmo hermeneuta é chamado a ficar atento a dois princípios fundamentais fixados pela Constituição da República: a Dignidade da Pessoa Humana e o valor social do trabalho, para que, de fato, a Ordem Econômica fundada na valorização social do trabalho humano possa realmente buscar o Pleno Emprego (BRANCO, 2007, p. 60).
}

Destarte, há de se visualizar as potencialidades transformadoras que são trazidas com as cláusulas principiológica constitucionais da valorização do trabalho humano e do reconhecimento do valor social do trabalho (GRAU, 2008), as quais se mostram como um dos alicerces para a efetiva garantia da dignidade humana. Ou seja, a pergunta que se lança consiste na prevalência da Constituição, com a força de seus dispositivos em prol da dignidade da pessoa humana, ou da lex mercatoria, que converte tudo e todos em instrumento para a riqueza de poucos (MINISTÉRIO PÚBLICO DO TRABALHO EM MINAS GERAIS, s.d.). É esse o dilema dos velhos e, ainda, dos novos tempos.

\title{
5 Crise econômica, função social da empresa e dispensa coletiva
}

A propriedade privada se encontra inserida no rol dos direitos naturais do homem. O art. $5^{\circ}$, inciso XXII, diz que a propriedade em geral atenderá a sua função social. Tal disposição já se mostra suficiente para que toda forma de propriedade fosse intrinsecamente permeada daquele princípio constitucional, embora a Constituição não se limitasse apenas a isso. A instituição da propriedade privada e a sua função social foram reafirmadas como princípios da ordem econômica (art. 170, II e III), conforme elucida José Afonso da Silva (2011). 
O princípio incide sobre a estrutura e o conteúdo da propriedade, sobre a própria configuração do direito, e constitui elemento que qualifica a situação jurídica considerada, condicionando os modos de aquisição, uso, gozo e disposição dos bens (CARVALHO, 2011). Através da função social, a propriedade, sem deixar de ser privada, se socializou, com isso significando que deve oferecer à coletividade uma maior utilidade dentro da concepção de que o social orienta o individual (CARVALHO, 2011). Especialmente em relação aos meios de produção (SILVA, 2011). A liberdade de iniciativa está, deste modo, dirigida a finalidades comunitárias, visando garantir a dignidade das pessoas, de acordo com os ditames da justiça social (SOUZA, 2010).

Uma das grandes questões trazidas pelo debate sobre a função social da propriedade está ligada à possibilidade de um instituto jurídico mudar sua própria natureza econômica, sem, contudo, que haja qualquer modificação da lei. Para Gilberto Bercovici (2005), o instituto jurídico da propriedade teve um rico desenvolvimento em um tempo relativamente curto, ocorrendo uma total mudança econômica e social sem que houvesse mudado consideravelmente sua definição jurídico-legislativa, ao menos sob o ângulo do direito civil. Segundo Gilberto Bercovici (2005, p. 147):

A função social da propriedade não tem justificação socialista, antes é um conceito
próprio do regime capitalista, que legitima o lucro e a propriedade privada dos bens
de produção, ao configurar a execução da atividade do produtor de riquezas, dentro
de certos parâmetros constitucionais, como exercida dentro do interesse geral. A
função social passou a integrar o conceito de propriedade, justificando-a e
legitimando-a.

Quando se fala em função social não se está fazendo referência às limitações negativas do direito de propriedade, que atingem o exercício do direito de propriedade e não a sua substância. As transformações pelas quais passou o instituto da propriedade não se restringem ao esvaziamento dos poderes do proprietário ou à redução do volume do direito de propriedade, de acordo com as limitações legais (BERCOVICI, 2005).

A mudança ocorrida foi, então, a de mentalidade, deixando o exercício do direito de propriedade de ser absoluto, estando atualmente ultrapassada a afirmação constante da Declaração dos Direitos do Homem e do Cidadão, de 1789, considerando-a sagrada. A função social da propriedade atualmente corresponde a uma concepção ativa e comissiva do uso da propriedade; faz com que o titular do direito seja obrigado a se valer de seus poderes e faculdades no sentido do bem comum (CARVALHO, 2011). 
A função é o poder de dar à propriedade determinado destino, de vinculá-la a um objetivo. A função social da propriedade introduz, na esfera endógena do direito, um interesse que pode até mesmo não coincidir com o do proprietário, com o predomínio do social sobre o individual (CARVALHO, 2011). Devido ao princípio da função social, fica o proprietário jungido a observar desde o papel produtivo que deve ser desempenhado pela propriedade, passando pelo respeito à ecologia, até o cumprimento da legislação social e trabalhista pertinente aos contratos de trabalho (ORRUTEA, 1998).

Nessa seara, as empresas, que são consideradas o modelo típico de propriedade, apresentam-se como entidades econômicas e sociais que representam as principais atividades de produção de riquezas, sem as quais não se geram empregos para membros de famílias e tributos para Estado (SOUZA, 2010). Desse modo, o princípio da função social da empresa é, nada mais, do que um desdobramento direito do princípio social da propriedade que, orquestradamente, funcionam tornando efetivo o princípio da dignidade da pessoa humana (BRANCO, 2007).

Historicamente, no contexto da concepção do modelo de Estado Liberal, a empresa fora concebida como um ente jurídico dotado de potencialidade para a produção e transformação de bens. Caracterizava-se pela busca de mercados e incessante lucratividade, já que inserida num modelo de exploração capitalista, sem qualquer entendimento e ou comprometimento com a realidade social. A empresa era, portanto, uma atividade eminentemente econômica (ALMEIDA, 2003).

As alterações de natureza comercial, financeira, econômica e institucional ocorridas no ambiente internacional ampliaram a complexidade da atividade empresarial ao mesmo passo em que um novo perfil de Estado hospedou um modelo distinto de sistema jurídico. Aliandose esses aspectos, é certo que o desenho e a estrutura da empresa foram alterados, passando esse ente jurídico a desempenhar um papel mais relevante na sociedade contemporânea; desde então, passou a representar uma força socioeconômica-financeira determinada, com uma significativa capacidade para gerar riquezas, em sentido amplo. Tornou-se, portanto, uma atividade empreendedora com uma interessante plataforma de interação com a coletividade, capaz de modificar profundamente o seu entorno social (ORRUTEA, 1998).

Nas palavras do Papa João Paulo II (1991, online), que apresentou uma visão personalista e comunitária da empresa através da Carta Encíclica Centesimus Annus: 
O desenvolvimento integral da pessoa humana no trabalho não contradiz, antes favorece a maior produtividade e eficácia do próprio trabalho, embora isso possa enfraquecer estruturas consolidadas de poder. A empresa não pode ser considerada apenas como uma 'sociedade de capitais'; é simultaneamente uma 'sociedade de pessoas', da qual fazem parte, de modo diverso e com específicas responsabilidades, quer aqueles que fornecem o capital necessário para a sua actividade, quer aqueles que à colaboram com o seu trabalho. Para conseguir este fim, é ainda necessário um grande movimento associado dos trabalhadores, cujo objectivo é a libertação e a promoção integral da pessoa.

Assim, a mudança do paradigma das empresas passa a privilegiar a primazia do homem e do trabalho sobre o capital, porque valoriza a dignidade da pessoa no âmbito das organizações, extensiva às comunidades em que se inserem:

\begin{abstract}
Substituindo aquela visão da empresa calcada em fins individuais e liberais descontextualizados do sistema jurídico nacional e da própria essência do Estado Social e Democrático de Direito, obtém-se como regra - não mais como exceção uma natural restrição ao uso, gozo, posse e gerência da empresa como entidade jurídica e propriedade que é, exigindo-lhe, a partir de então, uma responsabilidade social que recai tanto sobre as conseqüências de seus atos e funções internas sobrevivência e continuidade -, como também sobre as externas - organização da produção e abastecimento -, ambas necessariamente fundamentadas e orientadas pelos Princípios da equiidade, da boa-fé e da proporcionalidade, de modo a temperar e a conformar a autonomia privada, expectativas sociais e fins sociais do Direito e, conseqüentemente, a inadmitir desarmonias entre meios e fins e a punir os abusos e desvios de poder, estabelecendo uma proporcionalidade de importância da empresa para a sociedade que numa parceria cíclica lhe deu a oportunidade de explorar seus recursos naturais (bens de uso comum ao povo) e seus "recursos" humanos (pessoas). (SOUZA, 2010, p. 79-80).
\end{abstract}

Deve ser ressaltado, inclusive, que a função social é um princípio que deve ser observado pelo intérprete (BERCOVICI, 2005). A compreensão dessa mutação levou à alteração do comportamento decisório dos dirigentes empresarias, como também, a visão da empresa simplesmente como agente econômico.

A atividade empresarial, igualmente, deve redefinir todos os seus conceitos e modificar a interpretação dos elementos que a compõem. Quer dizer, ao invés de ser entendida como meio de acúmulo de valores, a empresa deve ser observada como um sistema pelo qual se expressa a atividade humana no campo econômico, com objetivos múltiplos de realização pessoal do empresário e de todos que com ela colabora, assim, e notadamente, a sociedade civil na qual está inserida (ALMEIDA, 2003), conforme esclarecem Paulo Roberto Colombo Arnoldi e Taís Cristina de Camargo Michelan (2002, p. 248-249):

O paradoxo que parece defluir da nova concepção da empresa como sujeito de direito no Estado contemporâneo, é a indagação de se atribuir uma função social à empresa numa organização moldada sob a ótica capitalista. Isso não inviabilizaria as empresas por se atribuir funções outras que não as diretamente relacionadas à produção de riquezas? Essa postura não anularia ou dificultaria o fim último das mesmas, que é o 
lucro? Parece que não, e é importante dizer que essa instituição não irá renunciar à sua finalidade lucrativa ao voltar-se para a sua função social. È que as empresas, na atualidade, acabam sendo tão responsáveis quanto o Estado, no que se refere a assegura os direitos individuais do cidadão, dando-se ênfase na melhora não apenas do aspecto econômico, mas também do social e da comunidade na qual está inserida, o que, em última análise, beneficia todas as partes.

A destinação social das empresas passou a ser exigida no ordenamento jurídico brasileiro a partir da Constituição Federal, ao normatizar a economia do país. Os princípios do art. 170 vinculam a ordem econômica aos fins sociais, visando ao bem comum acima de finalidades meramente lucrativas. Por esse dispositivo, a liberdade de iniciativa empresarial está dirigida a fins comunitários, para garantir a existência digna das pessoas, segundo os ditames da justiça social: em uma ponta, gerar empregos com remuneração justa e benefícios adequados, garantindo condições dignas de vida; na outra, limitar o lucro arbitrário, os preços abusivos, infrações à ordem econômica (SOUZA, 2010).

Todavia, muito antes das normas constitucionais, a Teoria da Empresa com funções e com responsabilidades sociais já fora traçada pela Lei das Sociedades por Ações - Lei $n^{\circ}$ 6.404/76 - (BRASIL, 1976) - e atualizada pelo Código Civil - Título II, Direito de Empresa (BRASIL, 2002).

Conforme tratamento dispensado no Título II do Código Civil de 2002, não há dúvidas de que, sendo a empresa "a atividade economicamente organizada para a produção ou a circulação de bens e serviços" (BRASIL, 2002, online), o empresário, seu sujeito de direito, ao exercer a atividade econômica (direito), deve fazê-lo de modo a estabelecer (dever) uma conexão, estreita e inseparável, entre a produção ou circulação de bens e serviços e a função social, visando - em especial na esfera do Direito Constitucional do Trabalho - à geração e circulação de riquezas e à proteção da relação de emprego, em respeito ao princípio constitucional fundamental da dignidade da pessoa humana (BRANCO, 2007).

A partir do exposto, pode-se colocar em xeque o direito potestativo (porque ainda não regulamentado) de o empregador dispensar, de forma completamente arbitrária, seus funcionários em demissões coletivas, consoante à reflexão de Maria Cecília Máximo Teodoro e Aarão Miranda da Silva (2009, online):

Pelo exposto, questionam-se os atos das empresas em demitir inúmeros trabalhadores em curto período de tempo, sob o pretexto da inviabilidade econômica e financeira de manter os postos de trabalho diante da crise, optando por unilateralmente e na surdina "decidir" pela redução de empregos e encargos sociais, o que se designa por "dispensa coletiva dos trabalhadores, ou dispensa em massa ou demissão em massa dos trabalhadores", e assim por diante. O problema social das demissões coletivas se 
agrava quando a empresa ("não social") utiliza-se do subterfúgio de não avisar, de não negociar, de não encontrar alternativas por meio da negociação coletiva junto ao sindicato representante da categoria para evitar as demissões.

O aspecto econômico da empresa, que, de fato é muito importante, não pode sufocar, portanto, a sua dimensão social e moral. Em nome do princípio da centralidade humana, ela deve, em primeiro lugar, assumir o dever do desenvolvimento do mercado e das sociedades, com vistas à realização das finalidades humanas e sociais (WHITAKER, 2010).

Esse evolutivo repensar-se do Direito em relação à empresa, sob a lente da função social, afigura-se extremamente necessário; especialmente quando se tem em mira o conjunto de incontáveis relações e obrigações jurídicas (contratos) que despontam como feixe da atividade empreendedora e refletem, direta e gravemente, alterações substanciais no seio da sociedade. E, conforme Ana Paula Tauceda Branco (2007), isso se dá de modo especial para os trabalhadores.

\section{CONCLUSÃO}

Diante da internacionalização da economia, a crise financeira ocorrida em 2008 nos Estados Unidos da América surtiu efeitos avassaladores nos mercados globais. Por consequência lógica, todos estes fatores afetaram a empregabilidade em escala também global, causando o cotejamento de dispensas coletivas, dignidade dos trabalhadores, preservação de empregos e empresas.

No cenário gerado desde então, principalmente nos últimos anos, o Brasil tem sentido o agravamento desse quadro, repercutindo nocivamente no mundo do trabalho. Assim, o assunto se apresenta atual e de especial relevância, na medida em que os novos paradigmas ditados pela ordem econômica mundial se instalam em face do atual processo de globalização, refletindo nos países de economia dependente, como o Brasil, os seus efeitos mais perversos, como, por exemplo, o agravamento do desemprego e a piora na condição de vida dos trabalhadores.

Na perspectiva desse estudo, o assunto fora retratado sob o enfoque do caráter protetor dos direitos fundamentais trabalhistas, dada a sua incapacidade de garantir a preservação da dignidade humana a essa classe, principalmente em tempos de crise econômica.

E, assim, nota-se a imperativa necessidade de se modernizar e atualizar as garantias fundamentais aos trabalhadores brasileiros face à atual realidade econômica do país, no sentido 
de enfrentar os grandes desafios próprios desse ramo do direito, dentre os quais a crise do emprego se afigura o mais complexo.

\section{REFERÊNCIAS}

ALMEIDA, Maria Christina de. A função social da empresa na sociedade contemporânea: perspectivas e prospectivas. Argumentum Revista de Direito, Marília, v. 3, p. 141-152, 2003. Disponível em: http://www.unimar.br/biblioteca/publicacoes/pos/Direito_vol_03.pdf. Acesso em: 04 set. 2016.

ANTUNES, Ricardo Luis Coltro. O continente do labor. São Paulo: Boitempo, 2011.

ARNOLDI, Paulo Roberto Colombo; MICHELAN, Taís Cristina de Camargo. Novos enfoques da função social da empresa numa economia globalizada. Revista de Direito Privado, São Paulo, Revista dos Tribunais, v. 3, n. 11, p. 243-250, jul./set. 2002.

BERCOVICI, Gilberto. Constituição econômica e desenvolvimento: uma leitura a partir da Constituição de 1988. São Paulo: Malheiros Editores, 2005.

BRANCO, Ana Paula Tauceda. A colisão dos princípios constitucionais no direito do trabalho. São Paulo: LTr, 2007.

BRASIL. Constituição da República Federativa do Brasil de 1988. Planalto, Brasília, 5 out. 1988.

Disponível

em:

http://www.planalto.gov.br/ccivil_03/constituicao/ConstituicaoCompilado.htm. Acesso em: 04 set. 2016.

. Lei n 6.404 , de 15 de dezembro de 1976. Planalto, Brasília, 15 dez. 1976. Disponível em: http://www.planalto.gov.br/ccivil_03/leis/16404consol.htm. Acesso em: 04 set. 2016.

Lei $\mathrm{n}^{\circ}$ 10.406, de 10 de janeiro de 2002 (Código Civil). Planalto, Brasília, 10 jan. 2002. Disponível em: http://www.planalto.gov.br/ccivil_03/leis/2002/110406.htm. Acesso em: 04 set. 2016.

CARVALHO, Kildare Gonçalves. Direito constitucional. 17. ed. Belo Horizonte: Del Rey, 2011.

COSTA, Orlando Teixeira da. Direito coletivo do trabalho e crise econômica. São Paulo: LTr, 1991.

DELGADO, Maurício Godinho. Curso de direito do trabalho. 10. ed. São Paulo: LTr, 2011.

FERREIRA FILHO, Manoel Gonçalves. Curso de direito constitucional. 36. ed. rev. e atual. São Paulo: Saraiva, 2010.

GODOY, Arnaldo Moraes. Globalização e Direito: a mundialização do capital e seus efeitos no modelo normativo brasileiro. Argumentum Revista de Direito, Marília, v. 3, p. 49-80, 
2003. Disponível em: http://www.unimar.br/biblioteca/publicacoes/pos/Direito_vol_03.pdf. Acesso em: 04 set. 2016.

GONÇALVES, Antônio Fabrício de Matos; KNEIPP, Bruno Burgarelli Albergaria. Reestruturação produtiva, globalização e neoliberalismo: reflexos o modelo brasileiro e suas consequências na legislação trabalhista. Revista do Advogado, São Paulo, n. 121, a. XXXIII, p. 18-30, nov. 2013.

GRAU, Eros Roberto. A ordem econômica na Constituição de 1988. 13. ed. São Paulo: Malheiros Editores, 2008.

HOFFMAN, Helga. Desemprego e subemprego no Brasil. 2. ed. São Paulo: Ática, 1980.

JOÃO PAULO II, Carta Encíclica Centesimus Annus. Vaticano, 1 maio 1991. Disponível em: http://www.vatican.va/holy_father/john_paul_ii/encyclicals/documents/hf_jpii_enc_01051991_centesimus-annus_po.html. Acesso em: 04 set. 2016.

KON, Anita. Pleno emprego no Brasil: interpretando os conceitos e indicadores. Revista Economia e Tecnologia (RET), v. 8, n. 2, p. 5-22, abr.jun. 2012. Disponível em: http://www.economiaetecnologia.ufpr.br/revista/Volume\%208\%20n\%202/05\%20Anita\%20K on.pdf. Acesso em: 04 set. 2016.

LAMY, Marcelo. Metodologia da pesquisa jurídica: técnicas de investigação, argumentação e redação. Rio de Janeiro: Elsevier, 2011.

MARTINS, Sérgio Pinto. A continuidade do contrato de trabalho. São Paulo: Atlas, 2000.

MATTOSO, Jorge. Emprego e concorrência desregulada: incertezas e desafios. In: OLIVEIRA, Carlos Alonso Barbosa de; MATTOSO, Jorge Eduardo Levi. (Orgs.). Crise e trabalho no Brasil: Modernidade ou volta ao passado? São Paulo: Scritta, 1996.

MINISTÉRIO PÚBLICO DO TRABALHO EM MINAS GERAIS. Terceirização versus proteção constitucional. Belo Horizonte, s.d. Disponível em: http://www.prt3.mpt.mp.br/informe-se/noticias-do-mpt-mg/254-terceirizacao-versusprotecao-constitucional. Acesso em: 04 set. 2016.

MOCHÓN MORCILLO, Francisco; TROSTER, Roberto Luis. Introdução à economia. São Paulo: Makron Books, 1994.

ONU. Declaração Universal dos Direitos Humanos. 1948. Disponível em: http://unesdoc.unesco.org/images/0013/001394/139423por.pdf. Acesso em: 04 set. 2016.

ORRUTEA, Rogério Moreira. Da propriedade e sua função social no Direito Constitucional moderno. Londrina: Eduel, 1998.

PANCOTTI, José Antônio. Aspectos jurídicos da dispensa coletiva no Brasil. Revista do Tribunal Regional do Trabalho da 15 Região, Campinas, n. 35, p. 39-67, 2009.

RIFKIN, Jeremy. O fim dos empregos: o declínio inevitável dos níveis dos empregos e a redução da força global de trabalho. São Paulo: Makron Books, 1995. 
SANTOS, Enoque Ribeiro dos. Fundamentos do Direito Coletivo do Trabalho nos Estados Unidos da América, na União Europeia, no Mercosul e a Experiência Brasileira. Rio de Janeiro: Lumen Juris, 2006.

Enoque Ribeiro dos. O Direito do Trabalho e o desemprego. São Paulo: LTr, 1999.

SILVA, José Afonso da. Curso de direito constitucional positivo. 35. ed. São Paulo: Malheiros, 2011.

SINGER, Paul. Desenvolvimento e crise. São Paulo: DIFEL, 1968.

SOUTO MAIOR, Jorge Luiz. O direito do trabalho como instrumento de justiça social. São Paulo: LTr, 2000.

SOUZA, Carlos Aurélio Mota. Fundamentos humanistas do bem comum: Família, Sociedade, Estado. In: SOUZA, Carlos Aurélio Mota de; CAVALCANTI, Thais Novaes (Coord.). Princípios humanistas constitucionais: reflexões sobre o humanismo do Século XXI. São Paulo: Letras Jurídicas, 2010.

TAVARES, André Ramos. Direito Constitucional Econômico. 2. ed. São Paulo: Método, 2006.

TEODORO, Maria Cecília Máximo; SILVA, Aarão Miranda da. A imprescindibilidade da negociação coletiva nas demissões em massa e a limitação de conteúdo constitucionalmente imposta. Âmbito Jurídico, Rio Grande, XII, n. 64, maio 2009. Disponível em: http://www.ambito-

juridico.com.br/site/index.php?n_link=revista_artigos_leitura\&artigo_id=6082. Acesso em: 04 set. 2016.

WHITAKER, Maria da Carmo. Ética na empresa e nos negócios: uma meta a ser alcançada. In: SOUZA, Carlos Aurélio Mota de; CAVALCANTI, Thais Novaes (Coord.). Princípios humanistas constitucionais: reflexões sobre o humanismo do Século XXI. São Paulo: Letras Jurídicas, 2010. 